\title{
A NEW MODEL OF WORK ROLE PERFORMANCE: POSITIVE BEHAVIOR IN UNCERTAIN AND INTERDEPENDENT CONTEXTS
}

\author{
MARK A. GRIFFIN \\ The University of Sheffield \\ ANDREW NEAL \\ The University of Queensland \\ SHARON K. PARKER \\ The University of Sheffield
}

\begin{abstract}
We propose that interdependence in a work context determines to what extent work roles are embedded within a broader social system and, further, that uncertainty determines whether work roles can be formalized or whether they emerge through adaptive and proactive behavior. Cross-classification of task, team member, and organization member behaviors with proficiency, adaptivity, and proactivity produced nine subdimensions of work role performance. Ratings from 491 supervisors from 32 organizations and self-ratings from employees in two organizations ( $n$ 's $=1,228$ and 927) supported the proposed distinctions. Self-reports of proactivity were positively correlated with two external measures of proactivity.
\end{abstract}

The meaning of work performance in the field of organizational behavior has changed over the last 40 years. Research has shifted from a focus on jobs and their fixed tasks to a broader understanding of work roles in dynamic organizational contexts (Ilgen \& Hollenbeck, 1991). Traditionally, work performance was evaluated in terms of the proficiency with which an individual carried out the tasks that were specified in his or her job description. From this perspective, a "well-specified job" was one in which all of the behaviors that contributed to organizational goal attainment were captured in an individual's job description (Murphy \& Jackson, 1999). Effectiveness could then be evaluated as outcomes achieved by carrying out the specified behaviors of the job (Campbell, McCloy, Oppler, \& Sager, 1993).

The changing nature of work and organizations has challenged traditional views of individual work performance (Ilgen \& Pulakos, 1999). Two of

This research was supported by an Australian Research Council Large Grant (Grant No. A79601474) awarded to the first and second authors. The authors thank Alannah Rafferty, Claire Mason, Gillian Yeo, and Malcolm Douglas for their support for conducting this study. An earlier version of this paper was presented to the Society of Organizational Behavior, Australia, and we thank members for their helpful feedback. the major changes are the increasing interdependence and uncertainty of work systems (Howard, 1995). Early approaches to work performance did not account for the full range of behaviors that contribute to effectiveness when systems are uncertain and interdependent (Campbell et al., 1993; Murphy \& Jackson, 1999). In response to this limitation, new constructs have been introduced that encompass an expanded set of responsibilities. These constructs include citizenship performance (Smith, Organ, \& Near, 1983), contextual performance (Borman \& Motowidlo, 1993), adaptive performance (Hesketh \& Neal, 1999; Pulakos, Arad, Donovan, \& Plamondon, 2000), and proactivity (Crant, 2000; Frese \& Fay, 2001; Parker, Williams, \& Turner, 2006).

Table 1 identifies the main approaches to work performance that are in current use and lists their key constructs. As Rotundo and Sackett (2002) noted, partially overlapping constructs now proliferate within the performance literature. There is currently no theoretical framework for differentiating and integrating the various constructs that describe individual performance and its link to effectiveness. Although performance frameworks and taxonomies have been developed (e.g., Borman \& Motowidlo, 1993; Campbell et al., 1993; Johnson, 2003; Welbourne, Johnson, \& Erez, 1998), none captures the spectrum of recent performance constructs while providing a theoretical rationale for 
TABLE 1

Recent Frameworks Addressing Aspects of the Performance Domain

\begin{tabular}{|c|c|}
\hline Authors & Aspect \\
\hline Campbell et al., 1993 & $\begin{array}{l}\text { Whole performance domain } \\
\text { Job-specific task proficiency } \\
\text { Non-job-specific task proficiency } \\
\text { Written and oral communication } \\
\text { proficiency } \\
\text { Demonstrating effort } \\
\text { Maintaining personal discipline } \\
\text { Facilitating peer and team } \\
\text { performance } \\
\text { Supervision and leadership } \\
\text { Management and administration }\end{array}$ \\
\hline $\begin{array}{l}\text { Borman \& Motowidlo, } \\
\quad 1993\end{array}$ & $\begin{array}{l}\text { Task performance } \\
\text { Contextual performance }\end{array}$ \\
\hline $\begin{array}{l}\text { Welbourne et al., } \\
1998\end{array}$ & $\begin{array}{l}\text { Job role behavior } \\
\text { Career role behavior } \\
\text { Innovator role behavior } \\
\text { Team role behavior } \\
\text { Organization role behavior }\end{array}$ \\
\hline Johnson, 2003 & $\begin{array}{l}\text { Task performance } \\
\text { - Job-specific task proficiency } \\
\text { - Non-job-specific task proficiency } \\
\text { - Written and oral communication } \\
\text { proficiency } \\
\text { - Management and administration } \\
\text { - Supervision } \\
\text { - Conscientious initiative } \\
\text { Citizenship performance } \\
\text { - Conscientious initiative } \\
\text { - Personal support } \\
\text { - Organizational support } \\
\text { Adaptive performance } \\
\text { - Dealing with uncertain work } \\
\text { situations }\end{array}$ \\
\hline Borman et al., 2001 & $\begin{array}{l}\text { Citizenship performance } \\
\text { Conscientious initiative } \\
\text { Personal support } \\
\text { Organizational support }\end{array}$ \\
\hline Podsakoff et al., 2000 & $\begin{array}{l}\text { Helping behavior } \\
\text { Sportsmanship } \\
\text { Organizational loyalty } \\
\text { Organizational compliance } \\
\text { Individual initiative } \\
\text { Civic virtue } \\
\text { Self-development }\end{array}$ \\
\hline Pulakos et al., 2000 & $\begin{array}{l}\text { Adaptivity } \\
\text { Handling emergencies or crisis } \\
\text { situations } \\
\text { Handling work stress }\end{array}$ \\
\hline
\end{tabular}

TABLE 1

Continued

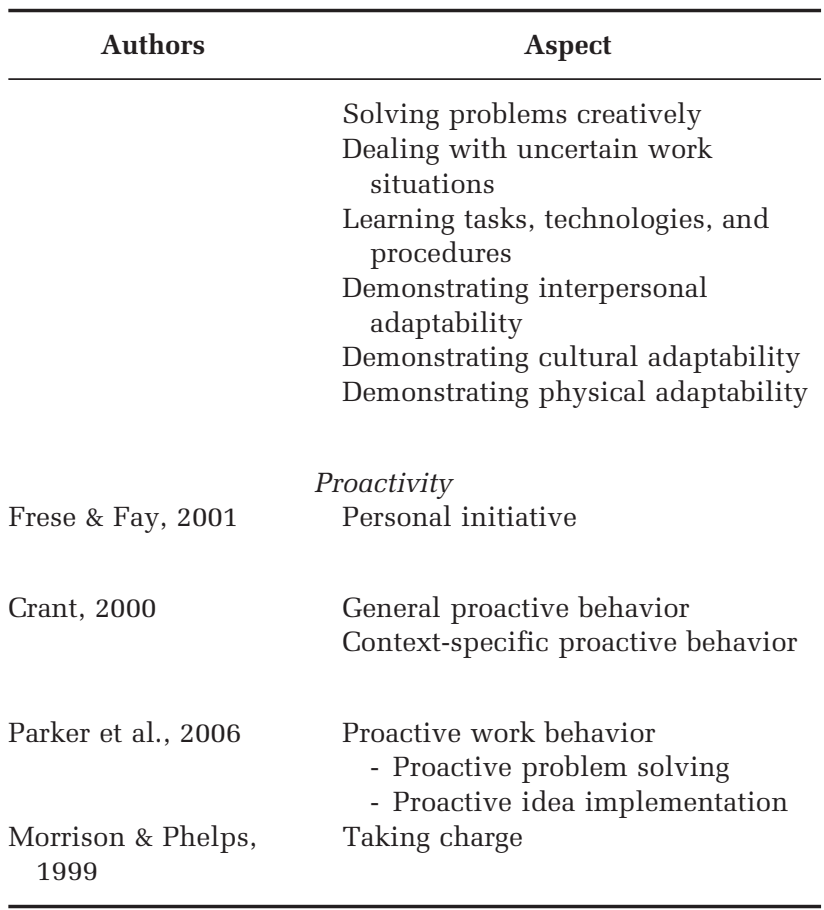

defining different dimensions and linking them to the context in which work is performed.

In this paper, we develop a new model of work role performance. We propose that context shapes and constrains the behaviors that will be valued in organizations, and we identify uncertainty and interdependence as two pervasive features of context that organizations must manage to be effective (e.g., Scott, 1987; Thompson, 1967). These contextual features suggest the types of behaviors that are valued in organizations and that are important for effectiveness. Uncertainty influences the extent to which work roles can be formalized and hence determines whether an individual can be effective by simply complying with the requirements of a work role or can only be effective by adapting to and initiating change. Interdependence determines the extent to which work roles are embedded in a broader social system and hence determines whether an individual can be effective by simply managing the responsibilities of his or her role as an individual within an organization or also needs to act to support the broader social context of the organization. Next, we use role theory to develop these arguments.

\section{THEORETICAL DEVELOPMENT}

The nature of work roles cannot be divorced from the contexts in which they are enacted (Ilgen \& 
Hollenbeck, 1999), so models of work role performance should incorporate theoretical features of organizational contexts (Hattrup \& Jackson, 1996). Unfortunately, it has proved difficult to explain how organizational context shapes and constrains the behaviors that are valued in organizations (Schuler \& Jackson, 1995). Role theory is an important approach to this problem as an effort to describe the full set of work responsibilities in a role and to encompass both organizational context and individual work behavior. Despite the relevance of role theory, previous applications have focused on the process of role development rather than on the way context relates to the dimensions of performance (Ilgen \& Hollenbeck, 1999). Although a number of researchers have proposed that role theory is useful for describing a broader set of work responsibilities (e.g., Ilgen \& Hollenbeck, 1991; Morgeson, Delaney-Klinger, \& Hemingway, 2005; Welbourne et al., 1998), this research has not formally included organizational context, nor has role theory been used to describe the dimensions of a work performance model.

\section{Uncertainty and Formalized versus Emergent Work Roles}

Almost all theories of organization emphasize the imperative for organizations to adapt in the face of uncertainty (e.g., Burns \& Stalker, 1961; Perrow, 1967; Thompson, 1967). Uncertainty is a defining characteristic of organizational contexts from the perspective of role theory (Katz \& Kahn, 1978) as well as sociotechnical systems theory (Trist, 1981), contingency theory (Duncan, 1972), and the behavioral approach to strategic human resource management (Schuler \& Jackson, 1987). In relation to work role performance, uncertainty in an organizational context occurs when the inputs, processes, or outputs of work systems lack predictability (Wall, Cordery, \& Clegg, 2001). Factors that create uncertainty include new competition, changing technologies, and evolving customer demands (Burns \& Stalker, 1961).

Uncertainty in an organizational context shapes the extent to which valued work behaviors can be formalized rather than left to emerge through adaptive and proactive behavior by role incumbents (Ilgen \& Hollenbeck, 1991; Murphy \& Jackson, 1999). When uncertainty is low, external forms of control can be used to ensure goal attainment (Cummings \& Blumberg, 1987). For example, work roles can be formalized using job descriptions that specify the tasks that people have to perform, the procedures that they have to follow, and the standards that are required. When uncertainty is high, external control is less appropriate because it is not possible to anticipate all contingencies, and it is more difficult to formalize task requirements (Ilgen \& Hollenbeck, 1991). In this case, work roles must emerge dynamically in response to changing conditions and demands (Katz \& Kahn, 1978). Thus, there is a greater requirement for role flexibility when an organizational context is more uncertain.

In view of the above distinction between formalized and emergent roles, we identify three different subdimensions of work role performance. The first, termed "proficiency," describes the extent to which an individual meets role requirements that can be formalized. It is possible to assess proficiency when the requirements of a work role are formalized because there is a clear standard against which these judgments can be made. The second dimension, "adaptivity," describes the extent to which an individual adapts to changes in a work system or work roles. The third dimension, "proactivity," describes the extent to which the individual takes self-directed action to anticipate or initiate change in the work system or work roles. Adaptivity and proactivity are important whenever a work context involves uncertainty and some aspects of work roles that cannot be formalized.

We describe proficiency, adaptivity, and proactivity in more detail below. It is important to note that we do not suggest that these different types of behavior are mutually exclusive or that organizational contexts are wholly certain or uncertain. When uncertainty is high, individuals still have to comply with the specified aspects of their roles that are predictable. For example, individuals might follow specified operating procedures when using technical equipment. Conversely, when uncertainty is low and many role requirements can be formalized, some need for adaptivity and proactivity may still exist. For example, individuals might proactively expand their roles. It is the relative importance of these different forms of behavior that varies, depending on the uncertainty of the environment.

\section{Interdependence and Individual Task versus Socially Embedded Behavior}

The distinction between task environment and social environment is fundamental to organizational theories such as sociotechnical systems theory (Trist, 1981). Borman and Motowidlo's (1993) concept of contextual performance was also built around the distinction of task and social context. We used role theory to build on this distinction. We argue that the interdependence in an organization 
highlights the value of behaviors that maintain and build a social context, as opposed to behaviors that only enable an individual to meet the responsibilities of his or her own individual task. Specifically, role theory describes organizations as systems of interdependent behaviors (Katz \& Kahn, 1978: 189). Interdependence occurs when the components of a system (e.g., individuals within a work group) need to cooperate to achieve shared goals (Cummings \& Blumberg, 1987). In interdependent systems, the behavior of an individual has an impact not only on the effectiveness of that individual, but also on the effectiveness of others, including groups, teams, and the organization as a whole.

The potential for an individual to contribute to effectiveness at a team or an organizational level depends on the embeddedness of his or her work role in the social context (Murphy \& Jackson, 1999). When the activities of a work role are independent of others, then there is a simple link between an individual's behavior and effectiveness as an employee. When the activities of work role are interdependent with other roles, the link between behavior and effectiveness is more complex. For example, helping a fellow team member might not contribute much to an individual's own effectiveness, but it might have a significant impact on the ability of the team to meet its goals. If a work role is interdependent with other members of an organization, then the behavior of an individual can contribute directly to the effectiveness of the organization as a whole. Defending the reputation of the organization, for example, might not contribute to the achievement of individual or team goals, but it is valuable for the broader organization (Borman \& Motowidlo, 1993).
As with our discussion of uncertainty, we do not suggest that organizational contexts can be wholly independent or interdependent or that the behaviors linked to this contextual dimension are mutually exclusive. By definition, all organizations include some degree of interdependence. What varies is the relative importance of the different types of behaviors. It is also important to note that behaviors that directly contribute to effectiveness at a given level (e.g., the individual level) can indirectly contribute to effectiveness at higher levels through an additive process of composition (Chan, 1998). For example, the sales figures achieved by an individual sales representative can contribute to the effectiveness of both a sales team and the individual. In this case, the link between sales performance and team effectiveness is indirect, because it is dependent upon the aggregation of outcomes from the individual to the team level.

\section{A New Model of Work Role Performance}

Murphy and Jackson described work roles as the "the total set of performance responsibilities associated with one's employment” (1999: 335). It has proved difficult for researchers to capture the full range of activities that contribute to effectiveness in uncertain and interdependent organizational contexts. Our model of work role performance addresses this issue by cross-classifying the three levels at which role behaviors can contribute to effectiveness (individual, team, and organization) and the three different forms of behavior (proficiency, adaptivity, and proactivity) into subdimensions of work role performance. This cross-classification is an important extension to existing

FIGURE 1

Model of Positive Work Role Behaviors

\begin{tabular}{|c|c|c|c|}
\hline $\begin{array}{c}\text { Individual Work } \\
\text { Role Behaviors }\end{array}$ & $\begin{array}{l}\text { Proficiency } \\
\text { Fulfills the prescribed or predictable } \\
\text { requirements of the role }\end{array}$ & $\begin{array}{c}\text { Adaptivity } \\
\text { Copes with, responds to, and } \\
\text { supports change }\end{array}$ & $\begin{array}{c}\text { Proactivity } \\
\text { Initiates change, is self- starting } \\
\text { and future-directed }\end{array}$ \\
\hline $\begin{array}{c}\text { Individual Task Behaviors } \\
\text { Behavior contributes to individual } \\
\text { effectiveness }\end{array}$ & $\begin{array}{c}\text { Individual Task Proficiency } \\
\text { e.g., ensures core task are completed } \\
\text { properly }\end{array}$ & $\begin{array}{c}\text { Individual Task Adaptivity } \\
\text { e.g., adjust to new equipment, } \\
\text { processes, or procedures in core } \\
\text { tasks }\end{array}$ & $\begin{array}{c}\text { Individual Task Proactivity } \\
\text { e.g., initiates better way of doing } \\
\text { core tasks }\end{array}$ \\
\hline $\begin{array}{l}\text { Team Member Behaviors } \\
\text { Behavior contributes to team } \\
\text { effectiveness rather than individual } \\
\text { effectiveness }\end{array}$ & $\begin{array}{l}\text { Team Member Proficiency } \\
\text { e.g., coordinates work with team } \\
\text { members }\end{array}$ & $\begin{array}{c}\text { Team Member Adaptivity } \\
\text { e.g., responds constructively to } \\
\text { team changes (e.g., new members) }\end{array}$ & $\begin{array}{l}\text { Team Member Proactivity } \\
\text { e.g., develops new methods to } \\
\text { help the team perform better }\end{array}$ \\
\hline $\begin{array}{c}\text { Organization Member } \\
\text { Behaviors } \\
\text { Behavior contributes to organization } \\
\text { effectiveness rather than individual } \\
\text { and team effectiveness }\end{array}$ & $\begin{array}{c}\text { Organization Member } \\
\text { Proficiency } \\
\text { e.g., talks about the organization in } \\
\text { positive ways }\end{array}$ & $\begin{array}{l}\text { Organization Member } \\
\text { Adaptivity } \\
\text { e.g., copes with changes in the } \\
\text { way the organization operates }\end{array}$ & $\begin{array}{l}\text { Organization Member } \\
\text { Proactivity } \\
\text { e.g., makes suggestion to improve } \\
\text { the overall efficiency of the } \\
\text { organization }\end{array}$ \\
\hline
\end{tabular}


performance models. We summarize the main elements of our model in Figure 1. In the next section, we briefly describe the main characteristic of each subdimension, explain how these characteristics relate to the performance constructs listed in Figure 1 , and use the example of a hospital nurse to illustrate the subdimensions.

Individual task proficiency. Individual task proficiency describes behaviors that can be formalized and are not embedded in a social context. These behaviors reflect the degree to which an employee meets the known expectations and requirements of his or her role as an individual. In essence, individual task proficiency is closely related to the concepts "task performance" (Borman \& Motowidlo, 1993; Johnson, 2003) and "job role behavior" (Welbourne et al., 1998), and incorporates Campbell and colleagues' (1993) concepts "job-specific," "non-job-specific," and "written and oral" task proficiency. This subdimension has been the traditional focus of performance research. In the case of a nurse, for example, this subdimension includes caring for patients by administering medications. The requirements of individual roles are relatively easy to define when uncertainty is low, and formal job descriptions commonly specify them. Traditional performance management systems focus almost entirely on this dimension of performance.

Team member proficiency. Team member proficiency describes behaviors that can be formalized and are embedded in a team or group context. These behaviors reflect the degree to which an individual meets the expectations and requirements of his or her role as a member of a team. Team member proficiency is similar to the concepts "personal support" (Borman, Buck, Hanson, Motowidlo, Stark, \& Drasgow, 2001), "helping behavior" (Podsakoff, MacKenzie, Paine, \& Bachrach, 2000), and "team role behavior" (Welbourne et al., 1998). The types of behaviors that are required for team member proficiency are well documented by the literature on team process. Marks, Mathieu, and Zaccaro defined team process as "members' interdependent acts that convert inputs to outcomes through cognitive, verbal, and behavioral activities directed toward organizing task work to achieve collective goals" (2001: 357). For a nurse, these types of behaviors might include monitoring progress toward team goals, helping other nurses to perform their tasks, and coordinating tasks. Within the citizenship literature, descriptions of these behaviors have tended to emphasize their discretionary nature (e.g., Borman \& Motowidlo, 1993; Podsakoff et al., 2000). However, our definition does not require these behaviors to be discretionary. These behaviors are often expected whenever peo- ple work in teams, even if they are not formally specified in job descriptions.

Organization member proficiency. Organization member proficiency describes behaviors that can be formalized and are embedded in an organizational context. These behaviors reflect the degree to which an individual meets the expectations and requirements of his or her role as a member of an organization. Organizational role proficiency is similar to the concepts "organizational support" (Borman et al., 2001; Johnson, 2003), "organizational loyalty and civic virtue” (Podsakoff et al., 2000), and "organization role behavior" (Welbourne et al., 1998). In the case of a nurse, behaviors such as defending organizational reputation and participating in organizational committees would be considered organization member proficiency. Again, our definition does not require these types of behaviors to be discretionary, as these contributions are often expected, particularly when work systems are highly interdependent.

Individual task adaptivity. Dynamic, unpredictable markets and rapidly changing technologies result in unanticipated changes to work requirements. To be effective in these contexts, individuals need to adapt to or cope with changes to their work roles and their environment. Individual task adaptivity reflects the degree to which individuals cope with, respond to, and/or support changes that affect their roles as individuals. For example, a nurse who accepts and copes well with a new procedure for administering medication demonstrates individual task adaptivity. Individual task adaptivity is important in light of factors such as the introduction of new technology, work redesign, and changes in strategy, all of which can require individuals to adjust their workplace behaviors. Like Johnson (2003), we regard Pulakos and colleagues' concept "dealing with uncertain work situations" (2000: 613) as a core element of this construct.

Our concept of adaptivity is somewhat narrower than Hesketh and Neal's (1999) concept of adaptive performance. The latter incorporates both the behaviors and the potential to enact adaptive behaviors, such as the capacity to cope with change. In our model, adaptivity refers only to behaviors.

Team member adaptivity. Uncertainty can also affect team roles. Kozlowski, Gully, Nason, and Smith (1999) argued that teams need to adapt to changes in their external environments, as well as to changes in themselves. Team member adaptivity reflects the degree to which individuals cope with, respond to, and/or support changes that affect their roles as members of a team. For example, team member adaptivity is shown by a nurse who adjusts well to a new supervision structure in her or his 
team. Team member adaptivity is similar to Pulakos and colleagues' (2000) "interpersonal adaptability." Kozlowski et al. argued that "adaptability is the capability of the team to maintain coordinated interdependence" (1999: 273) when dealing with nonroutine events and that this capability requires team members to modify their work roles as contingencies emerge. Moon and coauthors (2004) found that the extent to which team members adapted their roles and internal structures to align with their external environment positively influenced their performance.

Organization member adaptivity. Organization member adaptivity reflects the degree to which individuals cope with, respond to, and/or support changes that affect their roles as organization members. Previous analyses of adaptive performance (Hesketh \& Neal, 1999; Pulakos et al., 2000) have not differentiated organizational role adaptivity from individual and team role adaptivity. However, many of the changes to which employees are required to adapt occur at the organizational level. Mergers, restructuring, and business process reengineering are common examples of events that require individuals to adjust to organizational change. For example, if a hospital merges with another hospital, a nurse might need to adapt to, and support, the new structure. It is these kinds of behaviors we define as organizational role adaptivity. There are also processes through which organizational change results in change to team or individual roles. For example, when an organizational merger requires employees to perform new technical tasks, this requirement will best be assessed in terms of individual task adaptivity.

Individual task proactivity. When a work environment is highly uncertain, individuals, teams, and organizations must not only react and adapt to change, but must also anticipate and act upon the external environment in self-directed ways to achieve effective outcomes (Aragon-Correa, 1998). We defined individual task proactivity as the extent to which individuals engage in self-starting, futureoriented behavior to change their individual work situations, their individual work roles, or themselves. For example, a nurse might create a safer way of administering medication or might scan the environment to identify opportunities for better delivery of care. The requirement for individual task proactivity is increasing, given that pressures for continual improvement and innovation coexist with increasing decentralization (Campbell, 2000; Parker, 2000). Individuals need to identify improved ways of working under their own initiative, without relying on directions from supervisors (Crant, 2000; Parker, 1998). Related constructs in- clude "proactive behavior" (Crant, 2000; Parker et al., 2006), "taking charge" (Morrison \& Phelps, 1999), "personal initiative" (Frese, Kring, Soose, \& Zempel, 1996), and "innovator role behavior" (Welbourne et al., 1998). However, individual proactivity is distinct from "individual initiative" (Podsakoff et al., 2000) and "conscientious initiative" (Borman et al., 2001; Johnson, 2003) because the definitions for these latter constructs emphasize effort and persistence, rather than self-initiated and change-focused action.

Team member proactivity. Team member proactivity reflects the extent to which an individual engages in self-starting, future-directed behavior to change a team's situation or the way the team works. For example, a nurse might suggest a new roster to improve the way his or her team works or might put forward a better way of communicating among team members. Behaving proactively in relation to one's team is particularly important when teams are self-managing, as are autonomous work groups and many types of project teams. Like individual proactivity, team member proactivity differs from its corresponding citizenship constructs, namely "helping behavior" (Podsakoff et al., 2000) and "personal support" (Borman et al., 2001; Johnson, 2003). Definitions for these latter constructs emphasize the voluntary nature of these behaviors but do not emphasize the self-directed, changeoriented, or anticipatory actions that characterize proactive behavior.

Organization member proactivity. Organization member proactivity reflects the extent to which an individual engages in self-starting, future-directed behavior to change her or his organization and/or the way the organization works. For example, a nurse might contribute to a committee that is designing expanded work roles for nurses in a hospital or might come up with ideas to enhance a hospital policy. Such behaviors ensure that the organization as a whole develops and innovates, rather than promoting change only within narrow functional or departmental silos. Again, organization member proactivity differs from "organizational loyalty" (Podsakoff et al., 2000) and "organizational support” (Borman et al., 2001; Johnson, 2003) because of its emphasis on self-directed and future-directed change.

\section{THE PRESENT STUDY}

Our goal for the present study was to establish initial validity for the nine subdimensions that comprise the new model. We investigated the factor structure of items assessing the nine subdimensions, differential predictors of the subdimensions, 
and relationships between some of the subdimensions and external measures.

\section{Factor Structure of Subdimensions}

Our first step was to test whether individuals could distinguish among items designed to assess the nine subdimensions. We investigated both the self-ratings of employees and the ratings of supervisors because these two types of raters can exhibit different biases when assessing behaviors. Self-ratings are likely to be based on greater familiarity with the full range of behaviors in a role (Lance, Teachout, \& Donnelly, 1992) but are susceptible to distortion due to motivational processes such as self-enhancement (Farh \& Dobbins, 1989). Supervisor ratings are typically seen as less lenient but can show higher correlations among different behaviors if ratings are influenced by cognitive categorization processes such as an overall evaluation of the rated individual (Woehr, 1994). To provide a broad test of our model, we proposed that both employees rating their own behavior (Hypothesis 1a) and supervisors rating employee behavior (Hypothesis 1b) would exhibit distinctions among the nine subdimensions.

Hypothesis 1a. Employees systematically differentiate work behaviors in terms of our nine subdimensions when they self-rate behavioral items developed to assess each subdimension.
Hypothesis $1 b$. Supervisors systematically differentiate work behaviors in terms of our nine subdimensions when they rate employees using behavioral items developed to assess each subdimension.

\section{Differential Predictors}

Our next step used role theory to identify different predictors of work role behavior. Our goal was to identify constructs that should be stronger predictors of some subdimensions of role behavior than others. The hypothetically stronger relationships are depicted in Figure 2 and explained in detail below.

We began with the subdimension of individual task proficiency because it is the most closely related to traditional concepts of in-role task performance. Murphy and Jackson (1999) proposed that role clarity would predict these types of formally required behaviors. Role clarity describes the degree to which individuals are clear about the expectations for and requirements of their roles. Role clarity facilitates an external mode of control because the procedures and processes are specified, so role incumbents know what to do, how to do it, and how they are evaluated. We did not expect role clarity to be a particularly important predictor of team member proficiency or organization member proficiency because most current jobs do not provide clear expectations about the contextual and citizenship behaviors that support a team or the

FIGURE 2

Hypothetical Relationships between the Predictors and Subdimensions of Work Role Performance

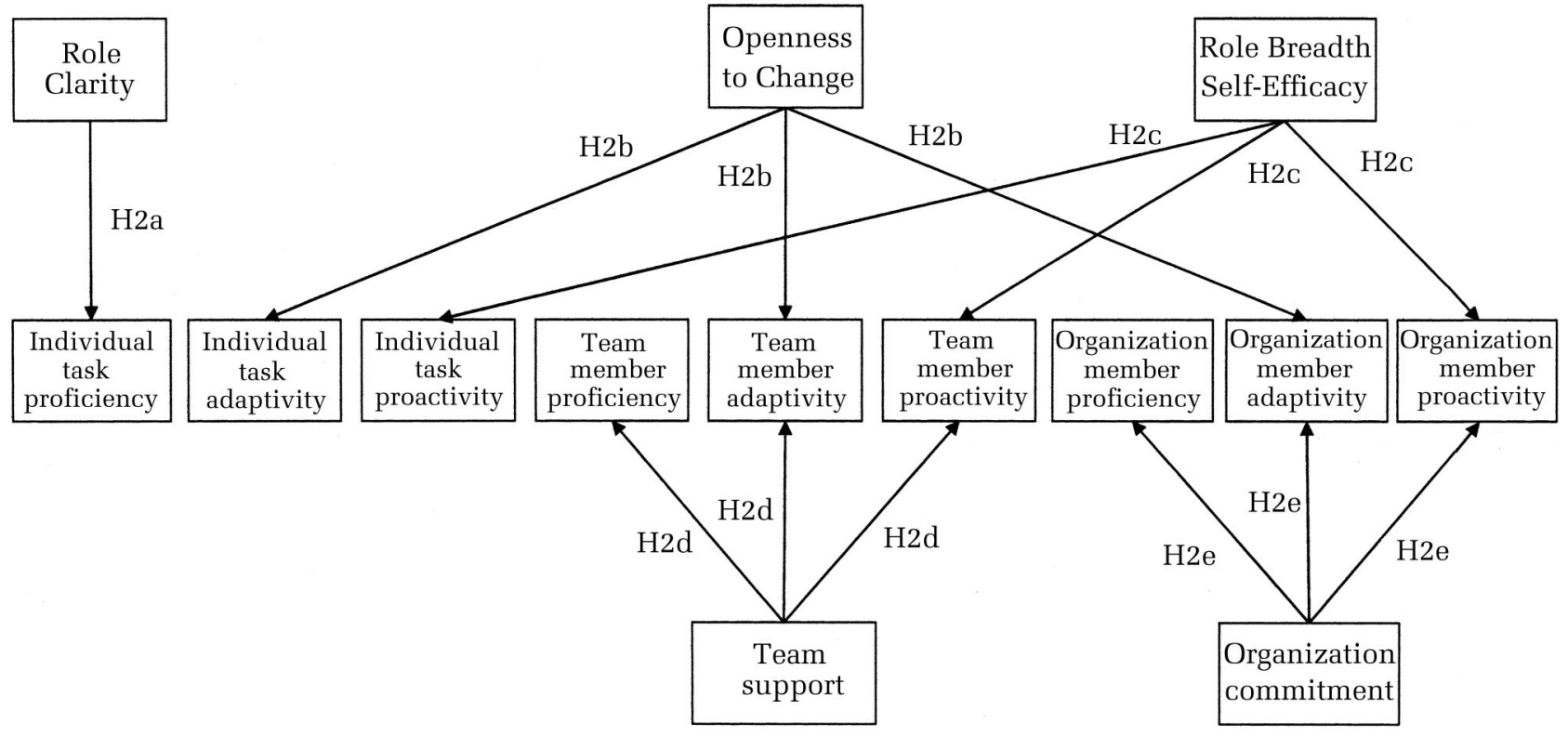


organization as a whole. Neither did we expect role clarity to be an important predictor of individual task adaptivity or individual task proactivity because specific requirements for these behaviors cannot be clarified in advance. Therefore, we proposed the following hypothesis:

Hypothesis 2a. Role clarity is more strongly related to the subdimension of individual task proficiency than to our other subdimensions.

Next, we identified constructs that would more strongly predict adaptive or proactive forms of behavior than proficient forms of behavior. In our model we propose that adaptivity and proactivity are important when role requirements cannot be formalized because of uncertainty in an organizational context. Role theory suggests that when there is uncertainty, some aspects of a role must emerge dynamically through interaction between the role incumbent and the environment. We expected that individuals who were more open to change would feel more positive about change in their organizational context and would be motivated to respond flexibly when confronting change (Schwartz \& Bilsky, 1990). Conversely, individuals with lower openness to change are likely to show a preference for more stable environments and task patterns (Liberman, Idson, Chen, Camacho, \& Higgins, 1999). We proposed that an individual's openness to change would increase her or his propensity to respond with adaptivity, according to the following hypothesis:

Hypothesis 2b. Openness to change is more strongly related to the subdimensions involving adaptivity (individual task adaptivity, team member adaptivity, and organization member adaptivity) than to our other subdimensions.

Proactivity is an emergent form of work role performance in which an individual engages in selfstarting, future-oriented behavior to change a situation. Role theory suggests that innovative change in work roles can create tension for role incumbents as well as for others in a work environment (Stryker \& Statham, 1985). Compared to adaptivity, proactive behaviors are more risky, and evidence suggests that individuals assess the likely consequences of their actions, such as whether the risks of taking charge outweigh the benefits (Morrison \& Phelps, 1999). Self-efficacy has been identified as a critical antecedent of proactive behavior because individuals who are confident in their capabilities are more likely to judge that their actions will be successful (e.g., Morrison \& Phelps, 1999). More specifically, "role breadth self-efficacy" (Parker,
1998, 2000), or individuals' confidence in their ability to take on more proactive, integrative, and interpersonal tasks, such as implementing new work procedures, has been shown to be a strong driver of proactive behaviors such as making suggestions (Axtell et al., 2000) and proactive problem solving, but not a predictor of more compliant behaviors, such as adhering to rules (Parker et al., 2006). We proposed the following hypothesis:

Hypothesis 2c. Role breadth self-efficacy is more strongly related to the subdimensions involving role proactivity (individual task proactivity, team role proactivity, and organization role proactivity) than to our other subdimensions.

We next identified predictors of behaviors directed toward different levels. According to our model, the opportunity for individuals to contribute to effectiveness at the team or organizational level depends on the social embeddedness of their work roles (Murphy \& Jackson, 1999). Role theory suggests that individuals will act to support a larger social entity such as a work group or organization when they feel part of the entity and recognize a bond of identity (Katz \& Kahn, 1978: 374). We proposed that when individuals perceive teammates as supportive and concerned for their welfare, they reciprocate by carrying out activities that contribute to the effectiveness of their team. Previous research has found that perceiving a supportive team environment is an important antecedent of behaviors contributing to team effectiveness (Colquitt, Noe, \& Jackson, 2002). Therefore, we proposed:

Hypothesis 2d. Perceptions of team supportiveness are more strongly related to the subdimensions involving team member behaviors (team member proficiency, team member adaptivity, and team member proactivity) than to our other subdimensions.

Under the same logic, role theory suggests that if individuals perceive that their broader organization is supportive and concerned for their welfare, they will be more likely to carry out activities that contribute to the effectiveness of the organization. We used individual's affective commitment to an organization to indicate the extent of positive and supportive relationship between the person and the organization. Organizational commitment has been strongly and consistently linked to perceptions of organizational support (Eisenberger, Fasolo, \& Davis-LaMastro, 1990). Organizational commitment has also been shown to predict some dimensions of performance but not others. For example, 
Becker and Kernan (2003) found that organizational commitment predicted unique variance in civic virtue, which was identified as having an organizational focus, but did not predict courtesy and inrole performance, which were conceptualized as more individually focused. We proposed the following hypothesis:

\section{Hypothesis 2e. Perceptions of organizational commitment are more strongly related to the subdimensions involving organization member behaviors (organization member proficiency, organization member adaptivity, and organiza- tion member proactivity) than to our other subdimensions.}

Our study used self-reported data, so we included negative affectivity to account for the possibility that dispositions might bias the perception of work characteristics and behaviors. We controlled for management hierarchical level and gender because these variables might be related to different work requirements as well as to different perceptions of a work environment.

\section{External Validity}

To provide evidence for external validity of the role performance model, we focused on the proactivity subdimensions. By definition, these behaviors are likely to change a workplace and create outcomes that external raters can observe. Two types of proactivity measure were obtained for one of the samples in our study. First, four members of the organizational development division rated the proactivity of work groups in the studied organization. We expected these ratings would correlate with the average self-ratings of individual proactive behavior within the groups. Second, for the same organization, we obtained the percentage of work group members who made suggestions through a formal suggestion system. We expected that the percentage of members making suggestions in each group would also correlate positively with the average self-ratings of proactive behavior. We proposed the following hypothesis:

Hypothesis 3. External ratings of work group proactivity and the percentage of members making improvement suggestions are positively related to aggregated measures of individual member proactivity, team member proactivity, and organization member proactivity.

\section{METHODS}

\section{Sample}

Three different samples participated in the study. The first sample comprised 491 supervisors from 32 Australian state government agencies who participated in a training evaluation study. Supervisors rated subordinates on the performance items described below. The mean age of supervisors was 42.3 years (s.d. $=8.82$ years). Ratings of single subordinates were provided by 78.2 percent of supervisors, and the remaining supervisors completed ratings for either two or three subordinates.

The next two samples comprised employees of two public sector organizations in Australia who completed an organization-wide survey. Employees completed a single questionnaire that included the performance items, predictor measures, and controls described below. Organization A comprised 1,360 employees (65 percent of whom responded) involved in a variety of occupations concerning management of the environment. Fiftyeight percent of the sample's members were women; the average age was 37.8 years (s.d. $=10.3$ years); and the average tenure in the organization was 5.7 years (s.d. = 5.6 years). Employees were located in 12 divisions comprising 141 work groups in a single state. The average number of respondents from each work group was 4.6 employees (s.d. $=5.9$ employees; range $=2-32$ employees). We classified the wide variety of occupations into four broad streams: administrative (42.5\%), technical $(7.6 \%)$, professional $(31.2 \%)$, and operational $(18.6 \%)$.

Organization B comprised 1,060 employees (of whom 60 percent responded) involved in specialist services in the health sector. Forty percent of the sample's members were female; the average age was 40.4 years (s.d. $=10.1$ years); and the average tenure in the organization was 10.6 years (s.d. $=9.4$ years). Employees were located in 197 work groups. The average number of respondents from each work group was 4.7 employees (s.d. $=4.2$ employees; range $=2-24$ ). Work groups were clustered into larger work units, and a subset of the larger units was the target of proactivity ratings described below. The size and number of these larger work units varied depending on the type of tasks undertaken. The mix of occupational classifications was administrative (46.0\%), technical $(8.7 \%)$, professional $(33.3 \%)$, and operational $(12.0 \%)$. Listwise deletion resulted in final samples of 1,228 employees in Organization A and 927 employees in Organization B. 


\section{Measures}

Performance. We used 27 items to assess the nine subdimensions of performance. Initially, we developed a pool of over 40 items as part of a larger project investigating perceptions of organizational climate. The items were either generated by us or adapted from previous measures of citizenship behavior (e.g., Smith et al., 1983) and extra-role behavior (e.g., Van Dyne \& LePine, 1998) to match the nine subdimensions of our performance model. The items were pilot-tested with employees in three organizations that were not involved in the current study ( $n$ 's $=1,758,1,400$, and 260). After using exploratory factor analysis to identify items with high loadings on the proposed factors and low loadings on other factors, we excluded items that showed high cross-loadings in the pilot data from subsequent data collection.

The Results section describes the content and psychometric properties of the final 27 performance items in detail. Table 2 reports the items and the corresponding subdimension for each, as well as factor loadings for all three samples. For all items, participants were asked to rate how often they had carried out the behavior over the past month on a scale ranging from 1 ("very little") to 5 (a "great deal"). The supervisor sample rated subordinates using only the 27 performance items. The employee self-ratings from the two samples were obtained together with other measures described below.

Predictors of performance. Measures of the predictor constructs were based on previously published scales that were trial-tested in pilot studies. To reduce the length of the questionnaire, we used subsets of items for some scales, basing item selections on analysis of the pilot data. Role clarity was assessed by three items from the School Organizational Health Questionnaire (Hart, Wearing, Conn, Carter, \& Dingle, 2000). We used results from the pilot studies to identify the three-highest loading items from the four-item scale. An illustrative item is, "My work objectives are always well defined." Responses ranged from 1 ("strongly agree") to 5 ("strongly disagree"). Alphas were .76 for Organization A and .77 for Organization B.

Openness to change was assessed by five items adapted from Miller, Johnson, and Grau (1994) that asked participants to report how they generally described themselves. An example item was, "I am somewhat resistant when work changes are proposed" (reverse-scored). Responses ranged from 1 ("strongly agree") to 5 ("strongly disagree"). Alphas were .74 for Organization $\mathrm{A}$ and .76 for Organization B.
Role breadth self-efficacy was assessed by five items with the highest factor loadings in the measure developed by Parker (1998). Role breadth selfefficacy refers to employees' perceived ability to carry out a broader and more proactive set of work tasks. Employees were asked how confident they would feel carrying out a range of proactive, interpersonal, and integrative tasks, such as contacting people outside their company (e.g., customers and suppliers) to discuss problems, analyzing a longterm problem to find a solution, and designing new procedures for their work group. The response scale ranged from 1 ("not at all confident") to 5 ("very confident"). Alphas were .86 for Organization A and .88 for Organization B.

Team support was assessed by three items adapted from Anderson and West (1994). The items asked employees to rate the extent to which their work group encouraged, communicated, and reviewed its processes. An example item was, "The methods used by my work unit to get the job done are often discussed." Responses ranged from 1 ("strongly agree") to 5 ("strongly disagree"). Alphas were .86 for Organization A and .85 for Organization B.

Organizational commitment was assessed by three items from Allen and Meyer's (1990) affective commitment scale. We selected items that had high factor loadings and showed appropriate internal consistency in the pilot studies. An example item was, "I feel emotionally attached to my organization." Responses ranged from 1 ("strongly agree") to 5 ("strongly disagree"). Alphas were .77 for Organization A and .75 for Organization B.

Negative affectivity was measured with 5 items from the neuroticism subscale of Costa and McCrae's (1989) NEO-PI five-factor personality inventory. We chose items from the full 12-item subscale that showed adequate reliability in the pilot studies and addressed all three facets of anxiety, depression, and hostility. Responses ranged from 1 ("strongly agree") to 5 ("strongly disagree"). Alphas were .72 for Organization $\mathrm{A}$ and .68 for Organization B.

Hierarchical management level was based on the system of position classifications used in the organizations and ranged from 1 ("base-level employee") to 9 ("senior executive service"). Gender was coded 1 ("male") or 2 ("female").

External proactivity measures. Two types of external proactivity measure were obtained, both from Organization B. The first measure was based on expert ratings of proactivity in 22 work units. These work units comprised multiple work groups, as described above, with the 22 work units containing a total of 52 smaller work groups. The expert raters $(n=4)$, who were members of a central 
TABLE 2

Results of Confirmatory Factor Analysis of Performance Items

\begin{tabular}{|c|c|c|c|}
\hline Items & Supervisors & Organization A & Organization B \\
\hline \multicolumn{4}{|l|}{ Individual task proficiency } \\
\hline Carried out the core parts of your job well & .88 & .83 & .85 \\
\hline Completed your core tasks well using the standard procedures & .85 & .79 & .92 \\
\hline Ensured your tasks were completed properly & .79 & .76 & .77 \\
\hline \multicolumn{4}{|l|}{ Individual task adaptivity } \\
\hline Adapted well to changes in core tasks & .88 & .81 & .82 \\
\hline Coped with changes to the way you have to do your core tasks & .90 & .83 & .85 \\
\hline Learned new skills to help you adapt to changes in your core tasks & .92 & .89 & .87 \\
\hline \multicolumn{4}{|l|}{ Individual task proactivity } \\
\hline Initiated better ways of doing your core tasks & .92 & .85 & .88 \\
\hline $\begin{array}{l}\text { Come up with ideas to improve the way in which your core tasks } \\
\text { are done }\end{array}$ & .91 & .93 & .91 \\
\hline Made changes to the way your core tasks are done & .90 & .84 & .87 \\
\hline \multicolumn{4}{|l|}{ Team member proficiency } \\
\hline Coordinated your work with coworkers & .81 & .65 & .61 \\
\hline Communicated effectively with your coworkers & .82 & .66 & .76 \\
\hline Provided help to coworkers when asked, or needed & .75 & .59 & .66 \\
\hline \multicolumn{4}{|l|}{ Team member adaptivity } \\
\hline $\begin{array}{l}\text { Dealt effectively with changes affecting your work unit (e.g., new } \\
\text { members) }\end{array}$ & .84 & .73 & .69 \\
\hline $\begin{array}{l}\text { Learnt new skills or taken on new roles to cope with changes in } \\
\text { the way your unit works }\end{array}$ & .92 & .86 & .70 \\
\hline Responded constructively to changes in the way your team works & .87 & .83 & .85 \\
\hline \multicolumn{4}{|l|}{ Team member proactivity } \\
\hline Suggested ways to make your work unit more effective & .91 & .88 & .82 \\
\hline $\begin{array}{l}\text { Developed new and improved methods to help your work unit } \\
\text { perform better }\end{array}$ & .91 & .88 & .92 \\
\hline Improved the way your work unit does things & .92 & .88 & .92 \\
\hline \multicolumn{4}{|l|}{ Organization member proficiency } \\
\hline $\begin{array}{l}\text { Presented a positive image of the organisation to other people } \\
\text { (e.g., clients) }\end{array}$ & .78 & .75 & .72 \\
\hline Defended the organisation if others criticized it & .89 & .80 & .82 \\
\hline Talked about the organisation in positive ways & .92 & .88 & .86 \\
\hline \multicolumn{4}{|l|}{ Organization member adaptivity } \\
\hline $\begin{array}{l}\text { Responded flexibly to overall changes in the organisation (e.g., } \\
\text { changes in management) }\end{array}$ & .74 & .82 & .83 \\
\hline Coped with changes in the way the organisation operates & .84 & .91 & .83 \\
\hline $\begin{array}{l}\text { Learnt skills or acquired information that helped you adjust to } \\
\text { overall changes in the organization }\end{array}$ & .91 & .89 & .69 \\
\hline \multicolumn{4}{|l|}{ Organization member proactivity } \\
\hline $\begin{array}{l}\text { Made suggestions to improve the overall effectiveness of the } \\
\text { organisation (e.g., by suggesting changes to administrative } \\
\text { procedures) }\end{array}$ & .74 & .86 & .85 \\
\hline $\begin{array}{l}\text { Involved yourself in changes that are helping to improve the } \\
\text { overall effectiveness of the organization }\end{array}$ & .90 & .85 & .85 \\
\hline Come up with ways of increasing efficiency within the organization & .91 & .89 & .87 \\
\hline
\end{tabular}

corporate development unit, were familiar with the operation of each work unit and had had personal contact with members of each unit over a period of 24 months. The work units covered a diverse geographical region but were all involved in similar work processes involving scientific testing procedures. Raters were asked to consider the extent to which the work group members generated suggestions, implemented new ideas, and anticipated problems and change in the workplace. Raters were 
asked to rate the proactivity of each work unit as a whole on a scale ranging from 1 ("little proactivity") to 5 ("very high proactivity"). The size of units ranged from 5 to 43 employees, with a mean size of 22.4 employees. The intraclass correlation $\operatorname{ICC}(2, \mathrm{k})$ over raters (where "k" was the four raters) was .62 for single-rater reliability and .86 for average rater reliability.

The second proactivity measure was based on another subsample from Organization B that participated in a centrally managed organization suggestion system. Twenty-four work units provided data on the number of suggestions made through the system. The 24 units comprised multiple feedback groups and ranged in size from 3 to 380 employees. The mean size was 52.8 (s.d. $=91.9$ ) employees, and the median size was 16 employees. We calculated the rate of suggestions by dividing the number of suggestions by the number of employees in each unit. The suggestion rate ranged from 0.02 to 2.67, with a mean of 0.45 (s.d. $=0.57$ ).

\section{RESULTS}

The first set of analyses assessed the factor structure of the 27 items in relation to the hypothesized nine-factor structure. We compared a series of models in the supervisor sample and the two employee samples. Table 3 shows the results of these comparisons, including values for the nonnormed fit index (NNFI), comparative fit index (CFI), and rootmean-squared error of approximation (Hu \& Bentler, 1999). From the fit of this model, we concluded that the nine-factor structure was the most appropriate representation of the factor structure of the 27 items. The correlations among subdimensions tended to be higher in the supervisor sample than in the employee samples; Tables 4 and 5 provide these statistics. However, the results support the hypotheses that employees (Hypothesis 1a) and supervisors (Hypothesis 1b) can distinguish among the nine subdimensions of behavior. As noted above, Table 2 reports the factor loadings of the performance items for all three samples.

To test the potential relationships between the predictor measures and the performance subdimensions, we conducted a series of analyses using data from the employee samples in Organizations A and B. We estimated a path model using scale scores computed from the average of the appropriate items for each performance subdimension. Scale scores rather than factor scores were used to simplify the analyses and to allow direct comparisons with results obtained from regression analyses. Table 6 reports the means, standard deviations, and alpha reliabilities for all measures. Alpha reli-

TABLE 3

Comparison of Alternative Factor Structures in the Three Samples ${ }^{\text {a }}$

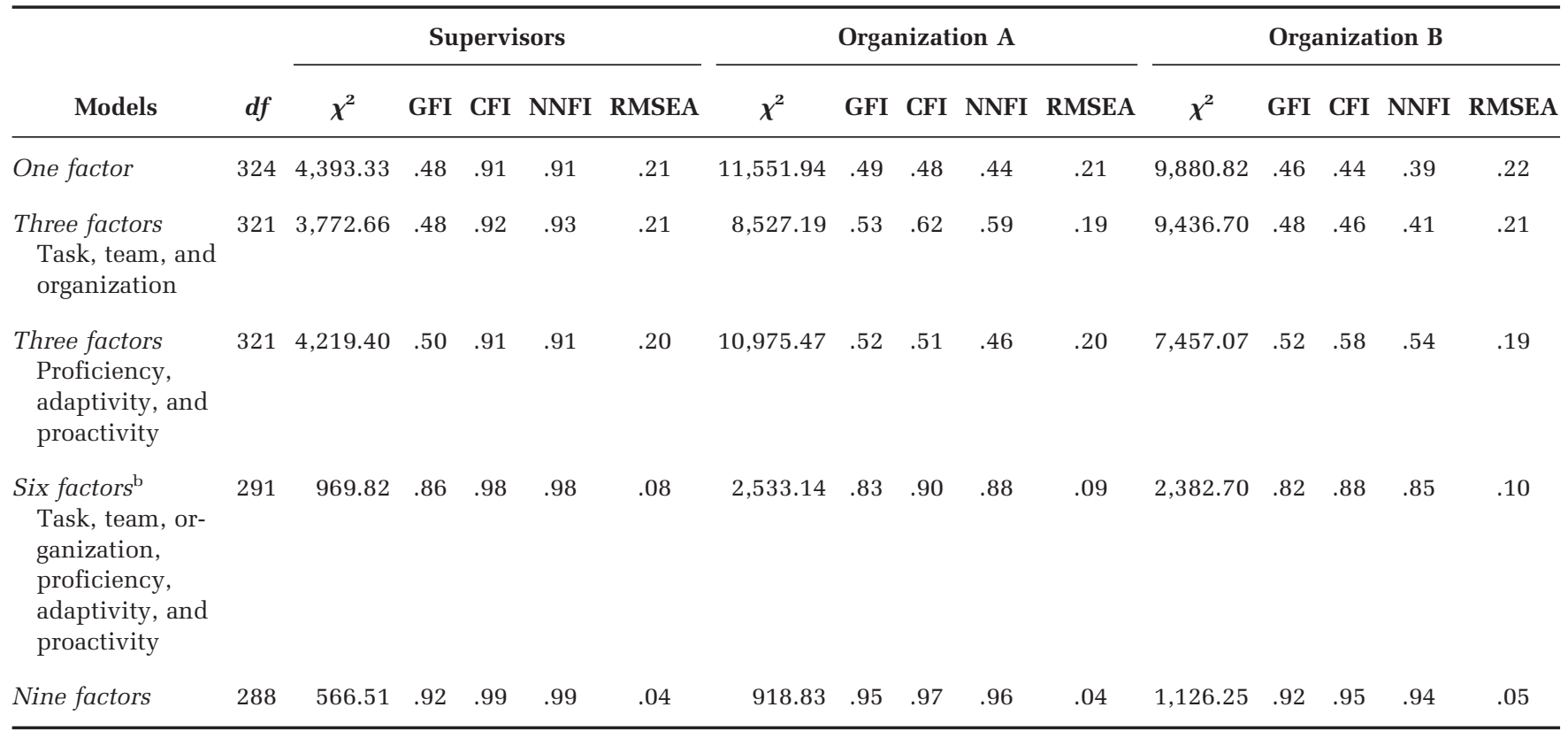

a Supervisors, $n=491$; Organization A, $n=1$,228; Organization B, $n=927$.

b The six-factor model tested whether each item loaded on a general factor defined by either the proficiency, adaptivity, or proactivity items, and also loaded on a general factor defined by either task, individual, or organization items. The proficiency, adaptivity, and proactivity factors were intercorrelated, as were the task, team, and organization factors. To ensure identification of the model, we did not estimate correlations between these sets of factors. 
TABLE 4

Correlations among the Latent Factors, Supervisor Sample ${ }^{a}$

\begin{tabular}{|c|c|c|c|c|c|c|c|c|c|c|c|}
\hline Variable & Mean & s.d. & $\alpha$ & 1 & 2 & 3 & 4 & 5 & 6 & 7 & 8 \\
\hline 1. Individual task proficiency & 4.09 & 0.69 & .87 & & & & & & & & \\
\hline 2. Individual task adaptivity & 3.90 & 0.82 & .93 & .71 & & & & & & & \\
\hline 4. Team member proficiency & 3.87 & 0.77 & .83 & .71 & .63 & .57 & & & & & \\
\hline 5. Team member adaptivity & 3.79 & 0.79 & .91 & .68 & .88 & .62 & .79 & & & & \\
\hline 6. Team member proactivity & 3.52 & 0.87 & .93 & .66 & .64 & .88 & .68 & .71 & & & \\
\hline 9. Organization member proactivity & 3.28 & 0.88 & .88 & .55 & .52 & .72 & .57 & .57 & .79 & .62 & .61 \\
\hline
\end{tabular}

${ }^{\text {a }}$ All correlations are significant at $\alpha=.05 . n=491$.

TABLE 5

Correlations among the Latent Factors, Organizations $A$ and $B^{a}$

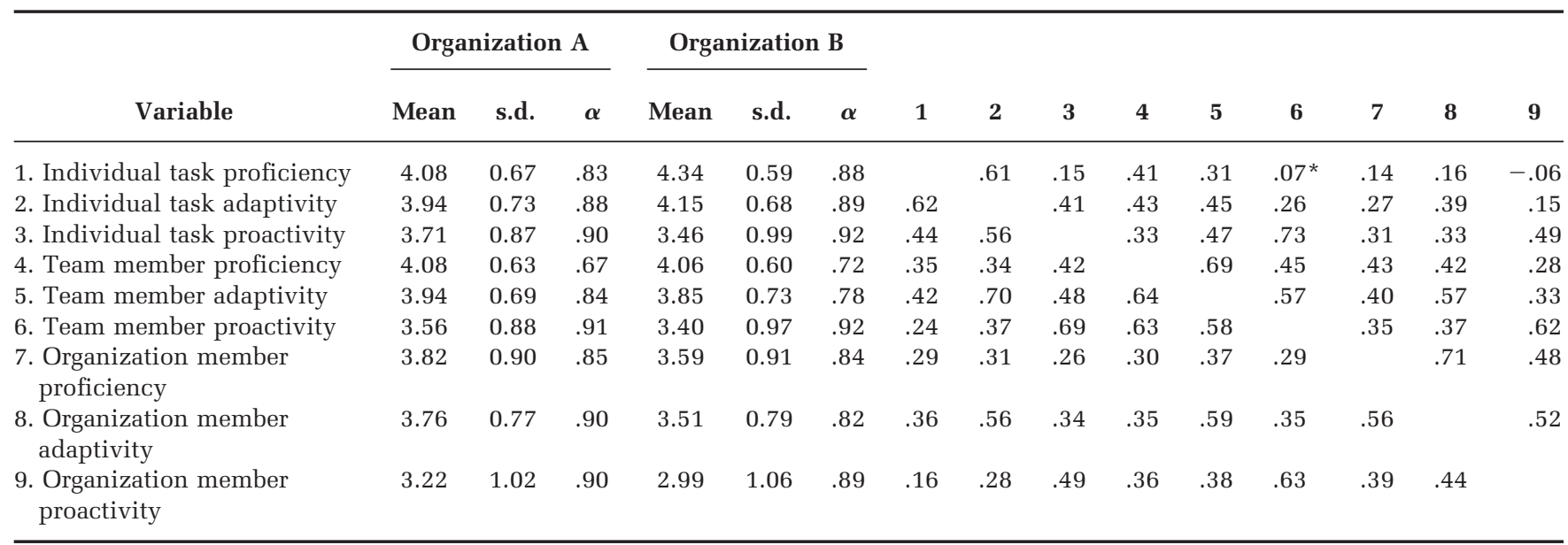

a The coefficients for Organization A are below the diagonal. Correlations greater than or equal to .06 for Organization A and .07 for Organization B are significant at $\alpha=.05$. Organization A, $n=1,228$; Organization B, $n=927$.

TABLE 6

Correlations among All Measures, Organizations A and $B^{a}$

\begin{tabular}{|c|c|c|c|c|c|c|c|c|c|c|c|c|c|c|c|c|c|}
\hline 1. Individual task $\mathrm{f}$ & & .55 & .15 & .35 & .27 & .08 & .13 & .15 & -.05 & .25 & .19 & .09 & .02 & .01 & .22 & -.18 & -.13 \\
\hline 2. Individual task adaptivity & .52 & & .35 & .37 & .46 & .2 & .22 & .34 & .13 & .22 & .35 & .21 & .08 & .10 & .16 & -.08 & -.19 \\
\hline 4. Team member proficiency & .27 & .25 & .33 & & .52 & .35 & .32 & .30 & .19 & .21 & .24 & .21 & .23 & .16 & .17 & .01 & -.12 \\
\hline 5. Team member adaptivity & .35 & .59 & .43 & .48 & & .49 & .32 & .47 & .28 & .24 & .30 & .17 & .26 & .20 & .12 & -.08 & -.16 \\
\hline 6. Team member proactivity & .22 & .33 & .63 & .50 & .50 & & .32 & .36 & .58 & .10 & .19 & .43 & .25 & .21 & -.09 & .17 & -.08 \\
\hline 9. Organization member proactivity & .14 & .25 & .44 & .29 & .31 & .56 & .34 & .39 & & .06 & .20 & .41 & .20 & .28 & -.10 & .23 & -.03 \\
\hline 10. Role clarity & .33 & .24 & .15 & .17 & .25 & .17 & .24 & .28 & .08 & & .13 & .07 & .48 & .27 & .05 & -.02 & -.24 \\
\hline 11. Openness to change & .15 & .36 & .18 & .13 & .33 & .16 & .19 & .44 & .18 & .11 & & .23 & .17 & .20 & .09 & .02 & -.22 \\
\hline 12. Role breadth self-efficacy & .14 & .25 & .35 & .24 & .24 & .39 & .20 & .21 & .41 & .12 & .24 & & .15 & .14 & -.24 & .36 & -.18 \\
\hline 13. Team support & .12 & .14 & .11 & .23 & .25 & .24 & .20 & .19 & .11 & .51 & .07 & .11 & & .35 & -.04 & .10 & -.19 \\
\hline 14. Organizational commitment & .10 & .15 & .14 & .17 & .19 & .17 & .45 & .29 & .26 & .17 & .13 & .16 & .19 & & -.03 & .10 & -.10 \\
\hline
\end{tabular}

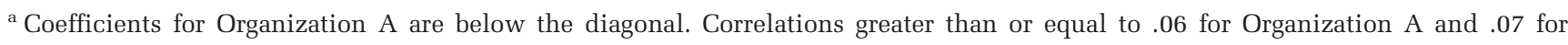
Organization B are significant at $\alpha=.05$. Organization A, $n=1,228$; Organization B, $n=927$. 
TABLE 7

Predictors of the Nine Performance Dimensions in Organizations $A$ and $B^{a}$

\begin{tabular}{|c|c|c|c|c|c|c|c|c|c|}
\hline \multirow[b]{3}{*}{ Variable } & \multicolumn{9}{|c|}{ Organization A } \\
\hline & \multicolumn{3}{|c|}{ Individual Task } & \multicolumn{3}{|c|}{ Team Member } & \multicolumn{3}{|c|}{ Organization Member } \\
\hline & Proficiency & Adaptivity & Proactivity & Proficiency & Adaptivity & Proactivity & Proficiency & Adaptivity & Proactivity \\
\hline Role clarity & $.30 * * *$ & $.15 * * *$ & $.09 * *$ & .06 & $.14 * * *$ & $.08 * *$ & $.14 * * *$ & $.19 * * *$ & -.01 \\
\hline Open to change & $.08 * *$ & $.30 * * *$ & $.08 * *$ & $.08 * *$ & $.27 * * *$ & $.09 * *$ & $.11 * * *$ & $.39 * * *$ & $.10 * *$ \\
\hline $\begin{array}{l}\text { Role breadth self- } \\
\text { efficacy }\end{array}$ & $.14^{* * *}$ & $.19 * * *$ & $.35 * * *$ & $.18 * * *$ & $.18^{* * *}$ & $.33 * * *$ & $.10^{* *}$ & $.07^{*}$ & $.33^{* * *}$ \\
\hline Team support & -.04 & .03 & .03 & $.16 * * *$ & $.12 * * *$ & $.12 * * *$ & .06 & .04 & .04 \\
\hline $\begin{array}{r}\text { Organizational } \\
\text { commitment }\end{array}$ & .02 & .02 & .05 & $.08 * *$ & $.05^{*}$ & .04 & $.30 * * *$ & $.13 * * *$ & $.17 * * *$ \\
\hline Gender & $.10^{* *}$ & .05 & $.13 * * *$ & $.08 * *$ & $.07 * *$ & .01 & .04 & $.09 * *$ & .03 \\
\hline Management level & $-.18 * * *$ & $-.12 * * *$ & -.05 & .05 & $-.06 *$ & $.06 *$ & .01 & .03 & $.09 * *$ \\
\hline Negative affectivity & -.05 & $-.09 * *$ & -.02 & .02 & -.01 & .04 & -.04 & -.05 & .01 \\
\hline$R^{2}$ & $.17 * * *$ & $.23 * * *$ & $.17 * * *$ & $.12 * * *$ & $.21 * * *$ & $.19 * * *$ & $.19 * * *$ & $.30 * * *$ & $.21 * * *$ \\
\hline
\end{tabular}

abilities were above .70 for all performance subdimensions except for team member proficiency $(\alpha=$ .67). Table 7 reports the correlations among all measures.

To test the hypotheses, we estimated a single path analysis model in which the five hypothesized variables and the three control variables were analyzed as predictors of the nine performance subdimensions. The predictors were all intercorrelated, as were the performance subdimensions. Table 7 shows the standardized path values for the prediction of the nine performance subdimensions by the eight predictors. For example, the first column of Table 7 shows the paths predicting individual task proficiency in Organization A. The bold numbers in Table 7 show those predictors that were hypothesized to be particularly important for each of the performance subdimensions.

We used equality constraints in the path analysis model to evaluate whether the paths from the predictors to hypothesized subdimensions were stronger than the paths to other subdimensions. The change in chi-square was used to test the statistical significance of the change in fit of the model. Because a path analysis model uses all available degrees of freedom, it results in a perfect fit to the data and cannot provide a comparison point for constrained models. To develop a point of comparison, we fixed the correlation between gender and organizational commitment. We fixed this particular correlation because it was not statistically significant in either Organization A or B. Once this correlation was fixed, the model provided a comparison point for tests of more constrained models.

Hypothesis 2a proposes that role clarity is a stronger predictor of individual task proficiency than the other subdimensions of performance. Supporting this hypothesis, the strongest path coefficient was the link between role clarity and individual task behavior in both organizational samples. To test the statistical significance of this stronger path, we estimated two different constrained models in which this path from role clarity to individual task performance was set equal to paths between role clarity and other performance subdimensions. First, we tested whether the path from role clarity to individual task proficiency was equal to the path from role clarity to individual task adaptivity and individual task proactivity. This constraint resulted in a significant decrease in model fit $(\Delta \chi 2[2, n=1,228]=26.44, p<.001$, for Organization $\mathrm{A}$, and $\Delta \chi 2$ [2, $n=927]=24.76, p<.001$, for Organization B). Second, we tested whether the path from role clarity to individual task proficiency was equal to the path from role clarity to team member proficiency and organization member proficiency. This constraint also resulted in a significant decrease in model fit $\left(\Delta \chi^{2}[2, n=1,228]=\right.$ 41.03, $p<.001$, for Organization A, and $\Delta \chi 2[2, n=$ 927] $=13.10, p<.001$, for Organization B). Therefore, Hypothesis 2a was supported.

Hypothesis $2 \mathrm{~b}$ proposes that openness to change 
TABLE 7

Continued

\begin{tabular}{|c|c|c|c|c|c|c|c|c|}
\hline \multicolumn{9}{|c|}{ Organization B } \\
\hline \multicolumn{3}{|c|}{ Individual Task } & \multicolumn{3}{|c|}{ Team Member } & \multicolumn{3}{|c|}{ Organization Member } \\
\hline Proficiency & Adaptivity & Proactivity & Proficiency & Adaptivity & Proactivity & Proficiency & Adaptivity & Proactivity \\
\hline $.25 * * *$ & $.18^{* * *}$ & -.05 & $.09^{*}$ & $.10^{* *}$ & -.05 & $.10^{* *}$ & $.09^{* *}$ & -.06 \\
\hline $.13 * * *$ & $.27 * * *$ & $.11 * *$ & $.14^{* * *}$ & $.23^{* * *}$ & $.08^{*}$ & $.13^{* * *}$ & $.29 * * *$ & $.08^{* *}$ \\
\hline$-.10^{* *}$ & $-.07^{*}$ & $.11 * *$ & $.14^{* * *}$ & $.13^{* * *}$ & $.17^{* * *}$ & $.12^{* * *}$ & $.07^{*}$ & $.08^{*}$ \\
\hline-.04 & .01 & $.09 * *$ & .04 & $.09 * *$ & $.11 * * *$ & $.40 * * *$ & $.30^{* * *}$ & $.23^{* * *}$ \\
\hline $.18^{* * *}$ & $.15^{* * *}$ & -.02 & $.21 * * *$ & $.12^{* * *}$ & .02 & $.09 * *$ & $.09 * *$ & .02 \\
\hline$-.16 * * *$ & $-.12 * * *$ & $-.14 * * *$ & .01 & $-.12 * * *$ & -.01 & -.01 & -.01 & $.08^{*}$ \\
\hline
\end{tabular}

is a stronger predictor of adaptivity subdimensions at each level (task, team, and organization) than proficiency and proactivity at each of these levels. Before testing the relative strengths of the paths, we tested whether openness to change was an equally strong predictor of adaptivity subdimensions at the three levels. The constrained model provided a poorer fit to the data, indicating that the paths were not equal at each level $(\Delta \chi 2[2, n=1,228]=26.32$, $p<.001$, for Organization A, and $\Delta \chi 2[2, n=927]$ $=6.80, p<.05$, for Organization B). Therefore, we compared each adaptivity subdimension to the proficiency and proactivity subdimension at the same level. Constraining the path from openness to change to adaptivity to be equal with the paths from openness to change to proficiency and from openness to change to proactivity resulted in a significant decrease in fit for the comparison at the task level $(\Delta \chi 2[2, n=1228]=73.05, p<.001$, for Organization A, and $\Delta \chi 2[2, n=927]=24.75, p<$ .001 , for Organization B), the team level ( $\Delta \chi^{2}[2$, $n=1,228]=46.99, p<.001$, for Organization A, and $\Delta \chi 2[2, n=927]=18.39, p<.001$, for Organization $\mathrm{B})$, and the organization level $(\Delta \chi 2(2, n=$ $1,228)=85.47, p<.001$, for Organization $\mathrm{A}$, and $\Delta \chi 2[2, n=927]=31.57, p<.001$, for Organization B). Therefore, all comparisons in both organizations supported Hypothesis 2b.

Hypothesis 2c concerns the paths from role breadth self-efficacy to proactivity. We propose that role breadth self-efficacy is a stronger predictor of proactivity than either proficiency or adaptivity at each level. We first tested whether role breadth self-efficacy was an equally strong predictor of proactivity at each level. For both Organizations A and B, a constrained model was not significantly different from the regression model, indicating that role breadth self-efficacy was an equally strong predictor of proactivity at each level $(\Delta \chi 2[2, n=1,228]=$ $3.39, p>.05$, for Organization $\mathrm{A}$, and $\Delta \chi 2[2, n=$ $927]=1.91, p>.05$, for Organization B). Therefore, our constrained models tested whether the three equal paths from role breadth self-efficacy to proactivity subdimensions were stronger than the paths from role breadth self-efficacy to proficiency and adaptivity at each level. The constrained models showed a significant decrement in fit for the task level $(\Delta \chi 2[2, n=1,228]=77.36, p<.001$, for Organization A, and $\Delta \chi 2[2, n=927]=73.01, p<$ .001 , for Organization B), team level $(\Delta \chi 2[2, n=$ $1,228]=78.38, p<.001$, for Organization A, and $\Delta \chi^{2}[2, n=927]=93.71, p<.001$, for Organization $\mathrm{B})$, and organizational level $\left(\Delta \chi^{2}[2, n=1,228]=\right.$ 103.61, $p<.001$, for Organization A, and $\Delta \chi^{2}[2$, $n=927]=101.48, p<.001$ for Organization B). Therefore, Hypothesis 2c was supported.

Hypothesis $2 \mathrm{~d}$ proposes that team support is a stronger predictor of team member behaviors than are the other subdimensions of performance. For both organizations, a constrained model was not significantly different from the regression model, indicating that team support was an equally strong predictor of all three team member subdimensions $(\Delta \chi 2[2, n=1,228]=1.24, p>.05$, for Organization $\mathrm{A}$, and $\Delta \chi 2[2, n=927]=5.84, p>.05$, for Organization B). Therefore, our next constrained models tested whether the value of the three equal paths from team support to team member subdimensions were stronger than the paths from team support to individual task behaviors and organization member behaviors. The constrained models showed a significant decrement in fit for the task behaviors $(\Delta \chi 2[31.87, n=1228]=77.36, p<.001$, for Organization $\mathrm{A}$, and $\Delta \chi 2[3, n=927]=52.84$, 
$p<.001$, for Organization B). However, only Organization A showed a significant decrement in fit for organization member behaviors $(\Delta \chi 2[3, n=1,228]$ $=9.32, p<.05)$. There was not a significant decrement in fit for Organization B $(\Delta \chi 2[3, n=927]=$ 5.47, $p>$.05). Therefore, Hypothesis 2c was supported for Organization A and partially supported for Organization B.

Hypothesis 2e proposes that organizational commitment is a stronger predictor of the organization member behaviors (i.e., organization member proficiency, adaptivity, and proactivity) than the other subdimensions. We first tested whether the three paths from organizational commitment to the three organization member behaviors were equal. There was a significant decrement in fit for both organizations, indicating that the paths were not equal $\left(\Delta \chi^{2}[2, n=1,228]=42.11, p<.001\right.$, for Organization $\mathrm{A}$, and $\Delta \chi 2[2, n=927]=24.33, p<.001$, for Organization B). Therefore, we compared each organization member subdimension to the corresponding dimensions at other levels. Constraining paths to be equal from organizational commitment to organization member proficiency, team member proficiency, and individual task proficiency resulted in a significant decrease in fit $(\Delta \chi 2[2, n=$ $1,228]=86.47, p<.001$, for Organization $\mathrm{A}$, and $\Delta \chi 2[2, n=927]=151.81, p<.001$, for Organization $B)$. There was also a significant decrease in fit when paths from organizational commitment to the adaptivity subdimensions $(\Delta \chi 2[2, n=1,228]=$ 18.39, $p<.001$, for Organization A, and $\Delta \chi 2[2, n=$ $927]=71.71, p<.001$, for Organization B) and the proactivity subdimensions $(\Delta \chi 2[2, n=1,228]=$ 28.50, $p<.001$, for Organization A, and $\Delta \chi 2[2, n=$ 927] $=18.50, p<.001$, for Organization B) were constrained to be equal. These results supported Hypothesis 2e.

Hypothesis 3 tests the external validity of the proactivity subdimensions for two sets of groups in Organization B. Table 8 shows the correlation between expert ratings of proactivity in 22 groups with the average self-report of all nine performance subdimensions in each group. Expert ratings were significantly correlated with average team member proactivity $(r=.37, p<.05)$ and average organization member proactivity $(r=.48, p<.05)$. Table 8 also shows the correlation between the suggestion rate in 24 groups and the average self-report level for the nine performance subdimensions. The suggestion rate was significantly, positively correlated with individual task proactivity $(r=.36, p<.05)$ and team member proactivity $(r=.36, p<.05)$. On the whole, these results support the hypothesis that external ratings of proactivity across units are re-
TABLE 8

Correlations between Aggregated Self-Reported Performance Measures and External Ratings

\begin{tabular}{lcc}
\hline \multicolumn{1}{c}{ Variable } & $\begin{array}{c}\text { Expert Ratings } \\
\text { of Group } \\
\text { Proactivity, } \\
\text { 22 Groups }\end{array}$ & $\begin{array}{c}\text { Suggestion } \\
\text { Rate per } \\
\text { Group, }\end{array}$ \\
$\mathbf{2 4}$ Groups \\
\hline Proficiency & & \\
Individual task proficiency & -.27 & .03 \\
Team member proficiency & .06 & $.37^{*}$ \\
Organization member & $.38^{*}$ & .12 \\
$\quad$ proficiency & & \\
Adaptivity & & .23 \\
Individual task adaptivity & .28 & .23 \\
Team member adaptivity & .28 & -.01 \\
Organization member & .32 & \\
adaptivity & & $.36^{*}$ \\
Proactivity & & $.36^{*}$ \\
Individual task proactivity & .24 & \\
Team member proactivity & $.37^{*}$ & \\
Organization member & $.48^{*}$ & \\
proactivity & & \\
\hline * $p$.05 & &
\end{tabular}

lated to aggregate ratings of proactivity within groups.

\section{DISCUSSION}

Welbourne and her colleagues (1998) argued that one of the major limitations of existing models of job performance is that they "lack a unifying theoretical framework" and that "without a theoretical underpinning, there is little guidance for choosing which dimensions of performance ... to include or exclude from a model" (1998: 541). Our model addresses this issue by identifying the dimensions of work role performance that contribute to effectiveness under different configurations of organizational interdependence and uncertainty.

\section{Theoretical Implications}

First, a major contribution of our study is the integration of adaptive and proactive behaviors into a comprehensive model. To date, adaptivity and proactivity have not been systematically integrated with other forms of behavior or distinguished from each other. For example, citizenship models have been criticized for emphasizing rather passive behaviors, such as compliance with procedures and punctuality (Frese \& Fay, 2001; Parker, 1998). Overlap can be seen in Pulakos and colleagues' (2000) concept of adaptive performance, which incorporates elements of proactivity (e.g., 
solving problems creatively). Similarly, Borman et al.'s (2001) concept of "conscientious initiative" incorporates elements of both proficiency (complying with formalized requirements) and proactivity (initiating change). Our approach provides a principled way of differentiating among these positive work role behaviors.

A further difficulty for integrative taxonomies has been the classification of behaviors into mutually exclusive categories. For example, Van Scotter and Motowidlo (1996) found that supervisors' ratings of job dedication, a construct initially proposed as a subdimension of citizenship performance, could not be differentiated from their ratings of task performance. Schmitt, Cortina, Ingerick, and Wiechmann (2003) argued that adaptive performance did not fit neatly into a distinction between task performance and contextual performance. Johnson (2003) addressed this issue by allowing constructs to cross-load on multiple dimensions. We have taken this approach one step further by systematically cross-classifying every behavior on two underlying dimensions, thereby overcoming a serious problem encountered by other performance frameworks.

Second, considering the level at which behaviors contribute to effectiveness provides a wider and more systematic range of attributes with which to differentiate role behaviors than the traditional distinction between task and citizenship performance. Borman and Motowidlo (1993) proposed that task performance comprises behaviors that contribute to an organization's "technical core" and that are typically evaluated in terms of proficiency (i.e., individual task proficiency). Citizenship performance, on the other hand, incorporates behaviors that contribute to an organization's broader social and psychological environment (team member or organization member behaviors), and "the emphasis is not on the proficiency with which those tasks are carried out, but on the initiative taken to volunteer to carry them [out]" (Borman \& Motowidlo, 1993: 74). In this example, individual behaviors are associated with proficiency, and behaviors directed to higher levels are equated with proactivity. Our model expands this distinction by showing that different ways of behaving, whether proficient, adaptive, or proactive, can be directed to the individual, group, or organizational level. We believe that this refinement is a natural extension of the task/citizenship distinction prevalent in the performance literature.

Third, our results provide encouraging evidence that different predictors are associated with the proposed subdimensions. It has proved difficult for researchers to identify consistently differential pre- dictors of citizenship and task performance. Podsakoff and coauthors (2000) concluded, contrary to expectations, that dispositional variables were not stronger predictors of citizenship performance than incentives and rewards (Organ, 1988). In a separate meta-analysis, LePine, Erez, and Johnson examined the antecedents of citizenship behavior and concluded that subdimensions were "highly related to one another and that there are no apparent differences in relationships with the most popular set of predictors" (2002: 60). Our results are promising because the distinctions among predictors were based on theoretical characteristics of the performance dimensions. Further research should elaborate mechanisms through which the characteristics of people and situations influence behaviors within the specific subdimensions of the model.

Finally, our model extends understanding of the link between individual performance and effectiveness outcomes for organizations. We first identified two broad organizational goals that organizations must meet to be effective, the goals of managing interdependence and uncertainty. Then, by defining work role behaviors in terms of these goals, our model identifies individual behaviors that lead to effectiveness in organizations. This approach generates a range of testable propositions that can be investigated in future research. For example, our model suggests that the level of uncertainty in a task environment influences the extent to which different types of behaviors contribute to effectiveness. In stable environments, proficiency should be highly important. As the tasks in a work environment become more unpredictable, we expect that adaptivity and proactivity will make a larger contribution. Thus, our model can help clarify why previous studies examining the consequences of different behaviors have had inconsistent results (Podsakoff et al., 2000).

\section{Practical Implications}

The distinctions made in our model help to address a number of practical issues in performance management. First, the appraisal and reward of team member behaviors in organizations is increasingly important, yet notoriously difficult. Our model makes it clear that team-directed behaviors are distinct from individual task performance. Further, individuals can contribute to team outcomes directly via team member behaviors, or indirectly via the aggregated effect of individual task behaviors. The relative importance of these behaviors will vary depending on factors such as the level of task interdependence in a team. The model enables managers to specify more clearly the kinds of indi- 
vidual behaviors and outcomes that might be evaluated and rewarded.

A second area of difficulty in performance management is developing reward systems for citizenship behaviors. Morrison (1996) noted that citizenship behaviors are difficult to specify in advance and are typically not rewarded. Our construct of organization member proficiency helps managers to identify behaviors beyond individual task proficiency that benefit an organization and might be specified in advance. For example, for professors, "institution building" is a form of organization member proficiency that can be specified in advance and evaluated as part of an individual's role. These types of behaviors can be differentiated from individual task proficiency but included in formal job requirements.

A third advantage of our model of performance is its recognition of proactivity and depiction of roles as emergent and flexible rather than static. Job incumbents self-initiate new tasks; they can craft their own work roles (Wrzesniewski \& Dutton, 2001). Our model provides a way to incorporate such emergent and flexible behavior into performance evaluation processes in organizations. In essence, the model provides a way for managers to recognize elements of a broader performance domain and coach supervisors to observe and manage different types of positive work role behavior. Our measure provides a simple tool with which to assess and compare the performance of individuals over a wide range of subdimensions in a variety of situations.

\section{Limitations}

The present study has limitations. Some of our results are based on employee self-reports, which raises a question about external validity. Selfratings of performance have been shown to have lower validity than supervisor ratings (Hoffman, Nathan, \& Holden, 1991), and in general individuals appear to be biased toward judging their own behavior as meeting a higher standard than the behavior of others (Harris \& Schaubroeck, 1988). However, this bias should increase the correlation among measures and attenuate any differences among the proposed subdimensions.

Supervisor ratings showed higher correlations than the self-ratings. We expected that supervisors might show less differentiation among subdimensions because of a tendency to make overall evaluations of an individual (Woehr, 1994). Nevertheless, the higher correlations raise some concern about the extent to which observers make clear distinctions among all the subdimensions. The su- pervisors in our sample received no information about the nature of the subdimensions or training in how to rate subordinates. It is likely that support, such as frame of reference training, would increase supervisors' ability to distinguish among the subdimensions.

Our performance measures were designed to be generic in nature and broadly applicable over a range of organizations and job types. For this reason, we selected a small set of items that was representative of each construct. The number of items limits empirical development because it might mask a finer-grained dimensional structure. In practical terms, the items are not specific to particular workplaces and do not map the full variety of behaviors in which individuals may engage. However, it is important to develop a simple structure that can be replicated in diverse organizations. Our results suggest that we have been successful in this respect. It is possible to further enhance the measure by incorporating organization-specific and role-specific items. An alternative way of creating a performance appraisal instrument from the model could be to develop behaviorally anchored rating scales, or computerized adaptive rating scales (Borman et al., 2001), to assess each subdimension within the model.

A further limitation is that our evidence of external validity was limited to proactive behaviors. We focused on proactive behaviors because we reasoned those are the most easily observed at the group level. Nevertheless, external validation needs to be extended to the other forms of behaviors.

\section{Conclusion}

Substantial progress has been made toward understanding of the nature of work performance over the past 20 years, with the development of a wide range of new constructs in response to the increasing interdependence and uncertainty of modern work. Our model consolidates advances by providing a parsimonious structure for integrating these constructs. The model identifies similarities and differences among these constructs and brings greater clarity to a domain that is increasingly complex.

\section{REFERENCES}

Allen, N. J., \& Meyer, J. P. 1990. The measurement and antecedents of affective, continuance and normative commitment to the organization. Journal of Occupational Psychology, 63: 1-18.

Anderson, N. R., \& West, M. A. 1994. The Team Climate 
Inventory: Manual and user's guide. Windsor, U.K.: ASE/NFER-Nelson Press.

Aragon-Correa, J. A. 1998. Strategic proactivity and form approach to the natural environment. Academy of Management Journal, 41: 55-567.

Axtell, C. M., Holman, D. J., Unsworth, K. L., Wall, T. D., Waterson, P. E., Harrington, E. 2000. Shopfloor innovation: Facilitating the suggestion and implementation of ideas. Journal of Occupational \& Organizational Psychology, 73: 265-285.

Becker, T. E., \& Kernan, M. C. 2003. Matching commitment to supervisors and organizations to in-role and extra-role performance. Human Performance, 16: 327-348.

Borman, W., Buck, D. E., Hanson, N. A., Motowidlo, S. J., Stark, S., \& Drasgow, F. 2001. An examination of the comparative reliability, validity, and accuracy of performance ratings made using computerized adaptive rating scales. Journal of Applied Psychology, 86: 965-973.

Borman, W. C., \& Motowidlo, S. J. 1993. Expanding the criterion domain to include elements of contextual performance. In N. Schmitt, W. C. Borman, and associates (Eds.), Personnel selection in organizations: 71-98. San Francisco: Jossey-Bass.

Burns, T., \& Stalker, G. 1961. The management of innovation. London: Tavistock.

Campbell, D. J. 2000. The proactive employee: Managing workplace initiative. Academy of Management Executive, 14(3): 52-66.

Campbell, J. P., McCloy, R. A., Oppler, S. H., \& Sager, C. E. 1993. A theory of performance. In N. Schmitt, W. C. Borman, and associates (Eds.), Personnel selection in organizations: 35-69. San Francisco: Jossey-Bass.

Chan, D. 1998. Functional relationships among constructs in the same content domain at different levels of analysis: A typology of composition models. Journal of Applied Psychology, 83: 234-246.

Colquitt, J. A., Noe, R. A., \& Jackson, C. L. 2002. Justice in teams: Antecedents and consequences of procedural justice climate. Personnel Psychology, 55: 83-109.

Costa, P. T., \& McCrae, R. R. 1989. NEO-PI/FFI. Odessa, FL: PAR.

Crant, J. M. 2000. Proactive behavior in organizations. Journal of Management, 26: 435-462.

Cummings, T., \& Blumberg, M. 1987. Advanced manufacturing technology and work design. In T. Wall, C. Clegg, \& N. Kemp (Eds.). The human side of advanced manufacturing technology: 37-60. Chichester, U.K.: Wiley.

Duncan, R. B. 1972. Characteristics of organizational environments and perceived environmental uncertainty. Administrative Science Quarterly, 17: 313327.
Eisenberger, R., Fasolo, P., \& Davis-LaMastro, V. 1990. Perceived organizational support and employee diligence, commitment and innovation. Journal of Applied Psychology, 75: 51-59.

Farh, J., \& Dobbins, G. H. 1989. Effects of comparative performance information on the accuracy of selfratings and agreement between self- and supervisor ratings. Journal of Applied Psychology, 74: 606610.

Frese, M., \& Fay, D. 2001. Personal initiative: An active performance concept for work in the 21st century. In B. M. Staw \& R. L. Sutton (Eds.), Research in organizational behavior, vol. 23: 133-187. Greenwich, CT: JAI Press.

Frese, M., Kring, W., Soose, A., \& Zempel, J. 1996. Personal initiative at work: Differences between East and West Germany. Academy of Management Journal, 39: 37-63.

Harris, M. M., \& Schaubroeck, J. 1988. A meta-analysis of self-supervisor, self-peer, and peer-supervisor ratings. Personnel Psychology, 41: 43-62.

Hart, P. M., Wearing, A. J., Conn, M., Carter, N. L., \& Dingle, R. K. 2000. Development of the School Organisational Health Questionnaire: A measure for assessing teacher morale and school organisational climate. British Journal of Educational Psychology, 70: 211-228.

Hattrup, K., \& Jackson, S. E. 1996. Learning about individual differences by taking situations seriously. In K. R. Murphy (Ed.), Individual differences and behavior in organizations: 507-547. San Francisco: Jossey-Bass.

Hesketh, B., \& Neal, A. 1999. Technology and performance. In D. R. Ilgen \& E. D. Pulakos (Eds.), The changing nature of performance: Implications for staffing, motivation, and development: 21-55. San Francisco: Jossey-Bass.

Hoffman, C. C., Nathan, B. R., \& Holden, L. M. 1991. A comparison of validation criteria: Objective versus subjective performance measures and self- versus supervisor ratings. Personnel Psychology, 44: 601620.

Howard, A. (Ed.). 1995. The changing nature of work. San Francisco: Jossey-Bass.

Hu, L., \& Bentler, P. M. 1999. Cutoff criteria for fit indexes in covariance structure analysis: Conventional criteria versus new alternatives. Structural Equation Modeling, 6: 1-55.

Ilgen, D. R., \& Hollenbeck, J. R. 1991. The structure of work: Job design and roles. In M. D. Dunnette \& L. M. Hough (Eds.), Handbook of industrial and organisational psychology (2nd ed.): 165-207. Palo Alto, CA: Consulting Psychology Press.

Ilgen, D. R., \& Pulakos, E. D. 1999. Employee performance in today's organizations. In D. R. Ilgen \& E. D. Pulakos (Eds.), The changing nature of perfor- 
mance: Implications for staffing, motivation, an development: 21-55. San Francisco: Jossey-Bass.

Jackson, S. E., \& Schuler, R. S. 1995. Understanding human resource management in the context of organizations and their environments. In J. T. Spence, J. M. Darley, \& J. Foss (Eds.) Annual review of psychology, vol. 46: 237-264. Palo Alto, CA: Annual Reviews.

Johnson, J. W. 2003. Toward a better understanding of the relationship between personality and individual job performance. In M. R. Barrick \& A. M. Ryan (Eds.), Personality and work: 83-120. San Francisco: Jossey-Bass.

Katz, D., \& Kahn, R. 1978. The social psychology of organizations (2nd ed.). New York: Wiley.

Kozlowski, S. W. J., Gully, S. M., Nason, E. R., \& Smith, E. M. 1999. Developing adaptive teams: A theory of compilation and performance across levels and time. In D. R. Ilgen \& E. D. Pulakos (Eds.), The changing nature of performance: Implications for staffing, motivation, and development: 240-292. San Francisco: Jossey-Bass.

Lance, C. E., Teachout, M. S., \& Donnelly, T. M. 1992. Specification of the criterion construct space: An application of hierarchical confirmatory factor analysis. Journal of Applied Psychology, 77: 437-452.

LePine, J. A., Erez, A., \& Johnson, D. E. 2002. The nature of dimensionality of organizational citizenship behavior: A critical review and meta-analysis. Journal of Applied Psychology, 87: 52-65.

Liberman, N., Idson, L., Chen, Camacho, C., \& Higgins, E. 1999. Promotion and prevention choices between stability and change. Journal of Personality and Social Psychology, 77: 1135-1145.

Marks, M. A., Mathieu, J. E., \& Zaccaro, S. J. 2001. A temporally based framework and taxonomy of team processes. Academy of Management Review, 26: $356-376$.

Miller, V. D., Johnson, J. R., \& Grau, J. 1994. Antecedents to willingness to participate in a planned organizational change. Journal of Applied Communication Research, 22: 59-80.

Moon, H., Hollenbeck, J. R., Humphrey, S. E., Ilgen, D. R., West, B., Ellis, A. P. J, \& Porter, C. O. L. H. 2004. Asymmetric adaptability: Dynamic team structures as one-way streets. Academy of Management Journal, 47: 681-695.

Morgeson, F. P., Delaney-Klinger, K. A., \& Hemingway, M. A. 2005. The importance of job autonomy, cognitive ability, and job-related skill for predicting role breadth and job performance. Journal of Applied Psychology, 90: 399-406.

Morrison, E. W. 1996. Organizational citizenship behavior as a critical link between HRM practices and service quality. Human Resource Management, 35: 493-512.
Morrison, E. W., \& Phelps, C. C. 1999. Taking charge at work: Extra-role efforts to initiate workplace change. Academy of Management Journal, 42: 403-419.

Murphy, P. R., \& Jackson, S. E. 1999. Managing work-role performance: Challenges for 21st century organizations and employees. In D. R. Ilgen \& E. D. Pulakos (Eds.), The changing nature of work performance: 325-365. San Francisco: Jossey-Bass.

Organ, D. W. 1988. Organizational citizenship behavior: The good soldier syndrome. Lexington, MA: Lexington Books.

Parker, S. K. 1998. Role breadth self-efficacy: Relationship with work enrichment and other organizational practices. Journal of Applied Psychology, 83: 835852.

Parker, S. K. 2000. From passive to proactive motivation: The importance of flexible role orientations and role breadth self-efficacy. Applied Psychology: An International Review, 49: 447-469.

Parker, S. K., Williams, H., M., \& Turner, N. 2006. Modeling the antecedents of proactive behavior at work. Journal of Applied Psychology, 91: 636-652.

Perrow, C. 1967. A framework for the comparative analysis of organizations. American Sociological Review, 32: 194-208.

Podsdakoff, P. M., MacKenzie, S. B., Paine, J. B., \& Bachrach, D. G. 2000. Organizational citizenship behaviors: Critical review of the theoretical and empirical literature and suggestions for future research. Journal of Management, 26: 513-563.

Pulakos, E. D., Arad, S., Donovan, M. A., \& Plamondon, K. E. 2000. Adaptability in the workplace: Development of a taxonomy of adaptive performance. Journal of Applied Psychology, 85: 612-624.

Rotundo, M., \& Sackett, P. R. 2002. The relative importance of task, citizenship, and counterproductive performance to global ratings of job performance: A policy-capturing approach. Journal of Applied Psychology, 87: 66-80.

Schmitt, N., Cortina, J. M., Ingerick, M. J., \& Wiechmann, D. 2003. Personnel selection and employee performance. In W. C. Borman, D. R. Ilgen, \& R. J. Klimoski (Eds.), Handbook of psychology: Industrial and organizational psychology, vol. 12:. 565-593. Hoboken, NJ: Wiley.

Schuler, R. S., \& Jackson, S. E. 1987. Organizational strategy and organization level as determinants of human resource management practices. Human Resource Planning, 10(3): 125-141.

Schwartz, S. H., \& Bilsky, W. 1990. Toward a theory of the universal content and structure of values: Extensions and cross-cultural replications. Journal of Personality and Social Psychology, 58: 878-891.

Scott, W. R. 1987. Organizations: Rational, natural, and open systems. Englewood Cliffs, NJ: PrenticeHall. 
Smith, C. A., Organ, D. W., \& Near, J. P. 1983. Organizational citizenship behavior: Its nature and antecedents. Journal of Applied Psychology, 68: 653-663.

Stryker, S., \& Statham, A. 1985. Symbolic interaction and role theory. In C. Lindzey \& E. Aronson (Eds.), Handbook of social psychology: 311-378. New York: Random House.

Thompson, J. D. 1967. Organizations in action. New York: McGraw-Hill.

Trist, E. 1981. The evolution of sociotechnical systems. In A. Van de Ven \& W. Boyce (Eds.), Perspectives on organization design and behavior: 19-75. New York: Wiley.

Van Dyne, L., \& LePine, J. A. 1998. Helping and voice extra-role behaviors: Evidence of construct and predictive validity. Academy of Management Journal, 41: 108-119.

Van Scotter, J. R., \& Motowidlo, S. J. 1996. Interpersonal facilitation and job dedication as separate facets of contextual performance. Journal of Applied Psychology, 81: 525-531.

Wall, T. D., Cordery, J. L., \& Clegg, C. W. 2002. Empowerment, performance, and operational uncertainty. Applied Psychology: An International Review, 51: 146-169.

Welbourne, T. M., Johnson, D. E., \& Erez, A. 1998. The role-based performance scale: Validity analysis of a theory-based measure. Academy of Management Journal, 41: 540-555.

Woehr, D. J. 1994. Understanding frame-of-reference training: The impact of training on the recall of performance information. Journal of Applied Psychology, 79: 525-534.

Wrzesniewski, A., \& Dutton, J. E. 2001. Crafting a job: Revisioning employees as active crafters of their work. Academy of Management Review, 26: 179-201.

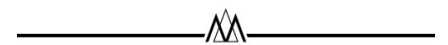

Mark A. Griffin (m.griffin@sheffield.ac.uk) is a professor of work psychology in the Institute of Work Psychology at the University of Sheffield. He received his Ph.D. in industrial/organizational psychology from the Pennsylvania State University. Mark's research addresses the nature of multilevel relationships between organizational contexts and individual processes. Current topics include leadership processes across multiple levels of analysis, safety outcomes in organizations, and the impact of individual performance on organizational outcomes.

Andrew Neal (andrew@psy.uq.edu.au) received his Ph.D. from the University of New South Wales. He is a senior lecturer in organizational and cognitive psychology at the University of Queensland. His research focuses on the determinants and consequences of work behavior from both micro and macro perspectives. Current topics include the development of training programs to enhance adaptive expertise; the development of computational models of task performance and motivation; an examination of the relationship between distal and proximal motivational processes over time; and the impact of safety climate, psychological climate and human resource management practices on employee behavior.

Sharon Parker (s.parker@sheffield.ac.uk) obtained her Ph.D. in occupational psychology from the University of Sheffield. She is a professor of work psychology and the director of the Institute of Work Psychology at the University of Sheffield. Sharon's research focuses on how work design and other organizational practices affect employees' performance, safety, well-being, and proactive performance. Current topics include an analysis of proactive work behaviors, the effect of work design on role breadth self-efficacy and other proactive motivation states, and a new theory of work design. 
Copyright of Academy of Management Journal is the property of Academy of Management and its content may not be copied or emailed to multiple sites or posted to a listserv without the copyright holder's express written permission. However, users may print, download, or email articles for individual use. 